\title{
Remote sensing of american maple in alluvial forests: a case study in an island complex of the Loire valley (France)
}

\author{
Hilaire Martin ${ }^{(1)}$, \\ Jean-Matthieu Monnet ${ }^{(2)}$, \\ Marie De Boisvilliers ${ }^{(3)}$, \\ Richard Chevalier ${ }^{(1)}$, \\ Marc Villar ${ }^{(4)}$
}

\begin{abstract}
Due to their particular topographic position between land and river, riparian forests are ecosystems rich in biodiversity. In France, along the Middle Loire (from Nevers to Angers), Black poplar (Populus nigra L.) forests are often in mixtures with the American maple (Acer negundo L.), introduced into the country in the $18^{\text {th }}$ century. We tested the detectability of American maple by LiDAR and very high-resolution multispectral imagery on an island complex. We found that coupling the point cloud height standard deviation with a vegetation index in the red, green and blue spectrums discriminated American maple with a success rate of more than $90 \%$.
\end{abstract}

Keywords: Acer negundo, American Maple, Box Elder, Populus nigra, Black Poplar, Airborne Laser Scanning, Remote Sensing, Exogenous Woody Species, Loire River

2017). In addition, the reintroduction of the European beaver in the 1970's indirectly favored colonization by the introduced species since beaver consumes the Black poplar but not the American maple.

In view of the above-mentioned elements, regular monitoring of riparian forests is important for their conservation and management, all the more so in a context of global warming, as these forests vary with the water level from one year to another and present multiple aspects. Thus, mapping these alluvial forests and updating the maps on a near-annual basis are the most appropriate tools to ensure quality monitoring. Currently, cartography has made tremendous progress thanks to Geographic Information Systems (GIS) software and satellite or aerial imagery (Dufour et al. 2013, Huylenbroeck et al. 2020). In France, the National Forest Inventory carries out a permanent inventory of forest resources and provides a great deal of data, including interactive maps. Data are collected at both the stand and tree levels. At the stand level, the forest cover type is in-
(1) INRAE Val de Loire, Site de Nogent-sur-Vernisson, Domaine des Barres 45290 Nogentsur-Vernisson (France); (2) Univ. Grenoble Alpes, INRAE, UR LESSEM, F-38402 St-Martind'Hères (France); (3) L'AVION JAUNE, 1 chemin du Fescau, 34980 Montferrier-sur-Lez (France); (4) INRAE Val de Loire, UMR 0588 INRA-ONF BioForA, 2163 Av. de la Pomme de Pin, CS 40001 Ardon, 45075 Orléans Cedex 2 (France)

@ Hilaire Martin (hilaire.martin@inrae.fr)

Received: Sep 13, 2019 - Accepted: Jul 08, 2020

Citation: Martin H, Monnet J-M, De Boisvilliers M, Chevalier R, Villar M (2020). Remote sensing of american maple in alluvial forests: a case study in an island complex of the Loire valley (France). iForest 13: 409-416. - doi: 10.3832/ifor3237-013 [online 2020-09-16]

Communicated by: Matteo Garbarino terpreted from infrared aerial images at a $50-\mathrm{cm}$ resolution. The final product is a vec tor layer (BD Foret V2) with polygons of 0.5 ha minimum attributed to 32 categories of species composition. However, neither AC nor PN has a category of its own, so this data cannot be used to monitor their spatial dynamics. At the tree level, many parameters are recorded on the NFI sample plots in different scientific domains such as dendrometry, botany and pedology (Hervé et al. 2014). Tree data include diameter, species and position, and height for a sub sample. However, precise plot locations are not publicly available, which prevents cross-analysis with external geographical data. Furthermore, plot density is 1 plot/ $2 \mathrm{~km}^{2}$ with surveys only every 5 years, thus making the data unsuitable for statistical analysis of small areas.

Aerial imagery provides only two-dimensional images that do not enable direct measurement of the vertical components of the forest canopy. However, in the beginning of the twenty-first century, technological advances in drones and active remote sensing, in particular through the development of new sensors, opened promising perspectives for accessing forest structures (Campbell et al. 2017). For instance, UAVs (Unmanned Aerial Vehicles) with Light Detection and Ranging (LiDAR) provide a three-dimensional geo-referenced point cloud corresponding to the surface objects that intercept the laser pulses from a scanner mounted on an aircraft (Balenović et al. 2013). Though the first uses of LiDAR were mainly devoted to digital terrain models (Wehr \& Lohr 1999), numerous applications in forestry have since been investigated.

An overview of the bibliography reveals that there are two main approaches to tree crown delineation from LiDAR data. The 
Fig. 1 - Study area. The Mareau-auxprés islands are located within the large National Natural Reserve of Saint-Mesmin, downstream from Orléans (Loiret, France).
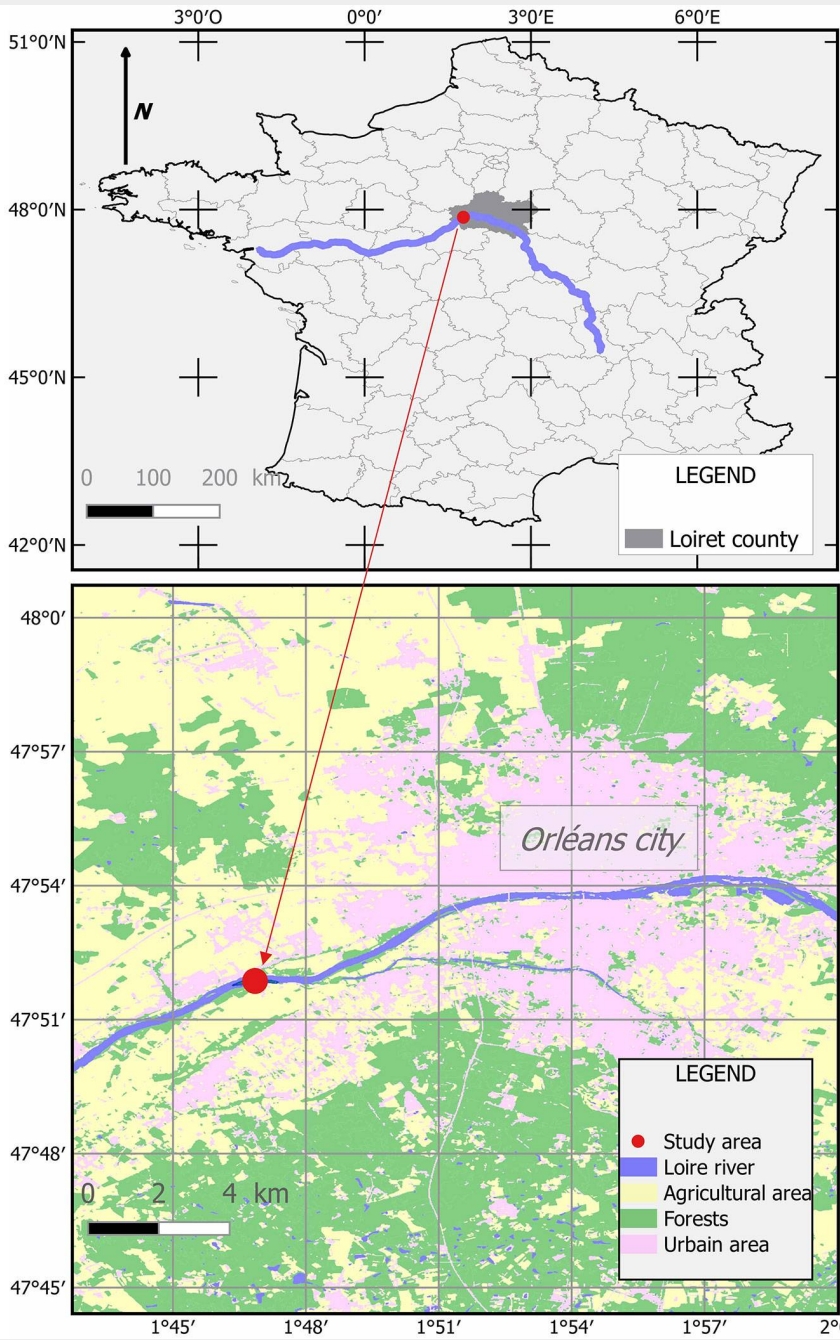

first one aims to model tree shape directly in the LiDAR cloud, but this process is quite complex (Monnet 2011, Jaafar et al. 2018). The second approach involves reducing the LiDAR cloud from 3D to 2D. This simplification is interesting because rasters have a longer development history than other approaches (Monnet et al. 2010, Zhen et al. 2016). The 3D-to-2D approach relies on the detection of treetops in the canopy height model ( $\mathrm{CHM})$. Then, the crowns are delineated with the watershed algorithm, which reverses the image and considers the crown envelope as a basin (Mei \& Durrieu 2004, Lindberg \& Holmgren 2017).

To ensure proper delineation of the trees, the algorithm's parameters must be carefully chosen in order to correspond to tree allometries, which are often species- and structure-specific. Applying watershed theory to the forest requires some intrinsic parameters for tree architecture, such as the distance to the nearest treetop, crown size, etc.

Our main goal was to test the ability of the various parameters in the tree segmentation function of the "lidaRtRee" package (Monnet 2018) running on free $R$ software to predict American maple stands in Black poplar island forests. Another objective of this technical paper is to assess the ability of combined LiDAR data and multispectral data acquired by unmanned aerial vehicles (UAVs) to distinguish American maple from Black poplar at the tree level. The test site was located in a French National Nature
Reserve along the Loire River. We focused on the use of open-source software tools with visual interpretation for training and validation steps to ensure that the method could be applied to larger areas.

\section{Material and methods}

\section{Study area}

The research was conducted in central France in the Loiret county, on the Mareauaux-Prés islands in the Loire River (within the boundaries of the Saint-Mesmin $\mathrm{Na}$ tional Nature Reserve) near the village of Mareau-aux-Prés (Fig. 1), approximately 10 $\mathrm{km}$ downstream from the city of Orléans ( $\left.47^{\circ} 51^{\prime} 51.88^{\prime \prime} \mathrm{N}, 01^{\circ} 46^{\prime} 52.84^{\prime \prime} \mathrm{E}\right)$. The total area of the experiment was about 10 ha and elevation ranged from 84 to $89 \mathrm{~m}$ a.s.l. The mosaic of four islands (Fig. 2) is mainly dominated by species from the Salicaceae family - adult black poplar and willow shrubs (Salix spp.) - except for the central island (C) where, in September 2012, the vegetation was uprooted and the island was leveled and lowered in order to maintain the flow capacity of the Loire river and to prevent floods. A new sedimentary bar appeared in spring 2013 and was colonized by Black poplar and willow seedlings; this island was therefore surveyed with the three other islands.

\section{Image and LiDAR acquisition}

Because terns were nesting on the banks, we were allowed to fly over the islands only after August 15. The UAV flights were carried out on 20 and 21 August 2017 by "L'Avion Jaune", a French aerial mapping operator using an octorotor FOX-C8 Onyxs$\operatorname{tar}^{\oplus}$. The level of the Loire River was one meter above zero, corresponding to summer low water. Eight successive flights occurred; three with a LiDAR sensor, then five others with a camera. LiDAR data were acquired by a YellowScan Surveyor ${ }^{\circledR}$ (YellowScan, Montferrier-sur-Lez, France), which included an onboard computer controlling three main components: a Velodyne laser scanner (VLP16), a Global Navigation Satellite System (GNSS) and an Inertial Navigation System (INS) built by Applanix (APX15). The flight height for the LiDAR was $45 \mathrm{~m}$ with a line spacing of $45 \mathrm{~m}$ and a sidelap of $60 \%$. The average point density per $\mathrm{m}^{2}$ was 215 . Multispectral imagery was acquired with a mapping system conceived by L'Avion Jaune. The latter con-

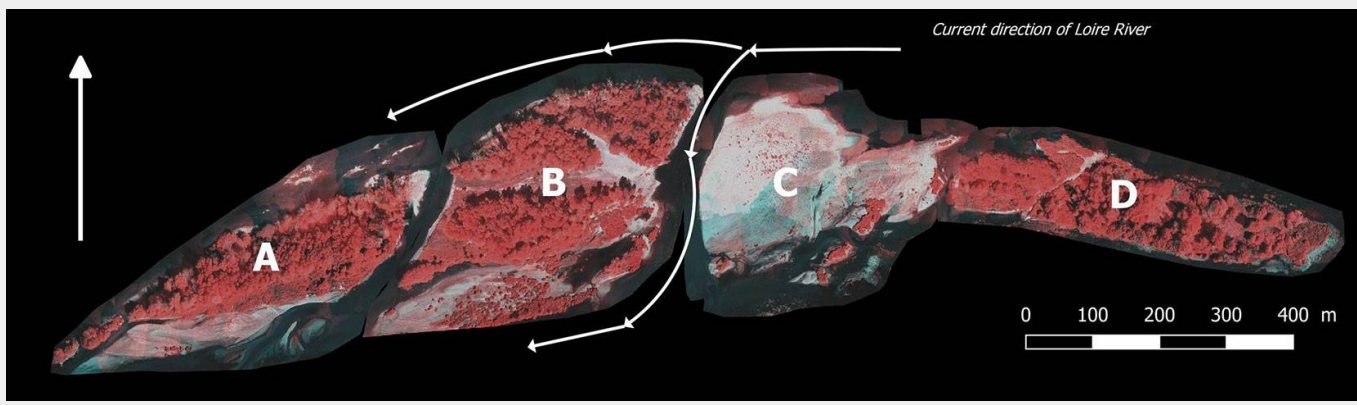

Fig. 2 - The mosaic of four islands. Letters indicate the name of the islands. 
sisted of a pair of identical digital singlelens reflex cameras (Canon ${ }^{\circledR}$ EOS 500D) one modified to assess the near infrared (NIR) wavelength, while the other unmodified camera assessed the visible wavelengths (RGB). The flight height for multispectral acquisition was $100 \mathrm{~m}$ with a sidelap of $60 \%$ and a frontlap of $80 \%$.

\section{Workflow}

The workflow was divided into three main steps (Fig. 3): (i) data pre-processing; (ii) tree crown delineation; (iii) model classification.

\section{Data pre-processing: LiDAR data}

Raw data processing was done by the mapping operator. LiDAR data were processed by successively running them through the PosPAC software by Applanix, a Surveyor QGIS plugin by YellowScan, and TerraMatch and TerraScan modules by TerraSolid. The classified point cloud was delivered in LAS format. The Digital Terrain Model (DTM) and the Canopy Height Model (CHM) were delivered in Geotif format at 0.2-m resolution. In order to compare different tree segmentations, we created a flood and non-flood forest mask within the mosaic of islands (Fig. 4.). Since American maple mainly colonizes river banks (Gurnell 2014), we excluded the hardwood forest (oak, elm, ash), located on higher terrain (in the non-flood area on island B), and retained only values between 0 and $2.5 \mathrm{~m}$ in height. This general mask was applied to all image treatments, including point clouds, DTM and CHM files, and orthophotos.

\section{Data pre-processing: multispectral} imagery and vegetation index

Multispectral imagery processing was performed according to scripts developed by L'Avion Jaune and the Correlator3D soft-

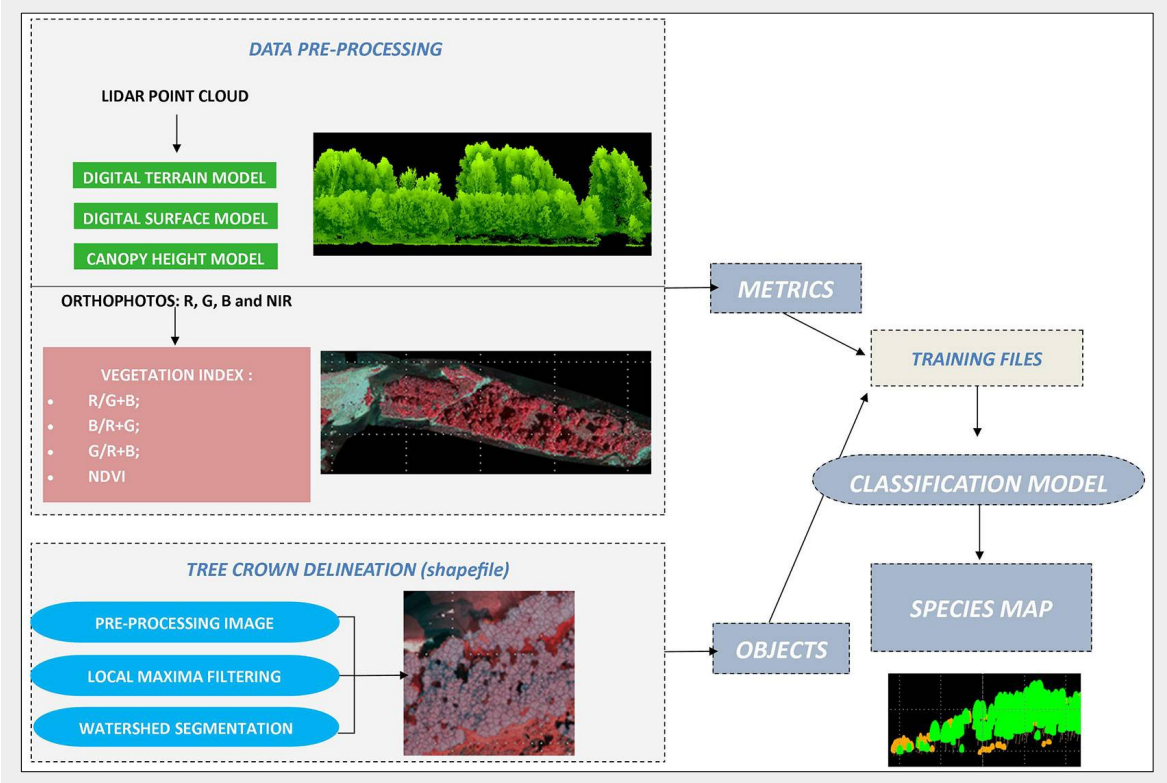

Fig. 3 - Workflow.

ware by Simactive. An orthophoto with inside the delineated crowns are used to four spectral bands (blue, green, red and select the discrimination variables in the near-infrared) was generated with a classification step. Tree segmentation was Ground Sample Distance (GSD) of $0.02 \mathrm{~m}$. performed with the "treeSegmentation" The orthophoto was resampled to $0.2 \mathrm{~m}$ function from the "lidaRtRee" package for consistency with the CHM.

Then four simple vegetation indices, ex- opr cluding the infrared wavelength, were based on a 3-phase approach, with each computed: (i) Red / (Green + Blue); (ii) phase requiring several values for paramGreen / (Red + Blue); (iii) Blue / (Green + etrization.

Red). We also computed the (iv) Normal- First, we applied filters to remove noise ized Difference Vegetation Index (NDVI - from the CHM file. A "salt-and-pepper" Rouse et al. 1973).

\section{Tree crown delineation}

This step is important because it determines the location and extent of the crowns. Subsequently, the data extracted
Fig. 4 - Canopy Height Model with non-riparian hardwood forest excluded.

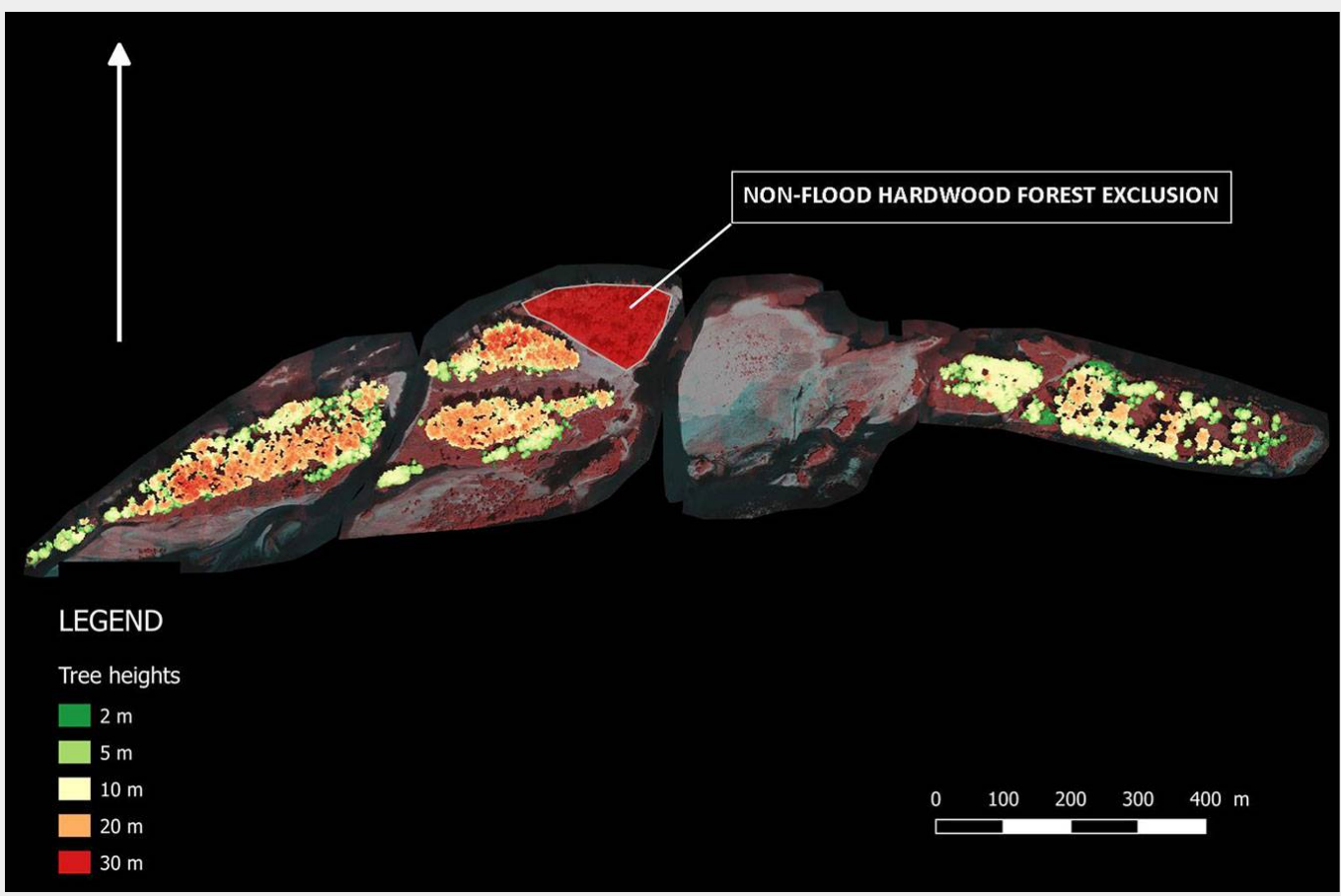


Tab. 1 - Parameters of the "treeSegmentation" function ("lidaRtRee" package). (*): Variables tested and their range of values.

\begin{tabular}{|c|c|}
\hline Name & Function \\
\hline nFilter, nISize & $\begin{array}{l}\text { Prevents "salt and pepper" where no laser points are recorded. We } \\
\text { used the default option "Closing" and } 3 \text { for size. }\end{array}$ \\
\hline sigma * & $\begin{array}{l}\text { Prevents branches in a crown from being considered as trees. We } \\
\text { tested from } 0.1 \text { to } 0.9\end{array}$ \\
\hline $\mathrm{dmin} / \mathrm{dprop}$ & $\begin{array}{l}\text { Treetop minimum distance to the next higher pixel and distance as a } \\
\text { proportion of height to the next higher pixel. } \\
\text { We set these two values at "0" due to crown overlap }\end{array}$ \\
\hline hmin & Minimum treetop height: $3 \mathrm{~m}$ due to tall nettles \\
\hline crownProp * & $\begin{array}{l}\text { Minimum height of tree crown as a proportion of treetop height. We } \\
\text { tested from } 0.1 \text { to } 0.9\end{array}$ \\
\hline crownMinH & Minimum crown height. We set this value at $3 \mathrm{~m}$. \\
\hline
\end{tabular}

a closing filter on a 3-pixel-wide neighbor- multiple branches from being detected as hood, which is the default parameter. We separate apices (Monnet 2011). Smoothing next applied a Gaussian filter to smooth intensity is driven by the sigma value of the out small local variations; this prevents Gaussian filter, which must be adapted to

Tab. 2 - Metrics computed.

\begin{tabular}{|c|c|c|}
\hline $\begin{array}{l}\text { Metrics } \\
\text { group }\end{array}$ & Metrics & Description \\
\hline \multirow{6}{*}{ 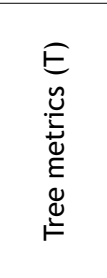 } & $\mathrm{s}$ & Crown surface \\
\hline & $\mathrm{v}$ & Crown volume \\
\hline & chm.sd & Height standard deviation \\
\hline & zskew & Skewness of height distribution \\
\hline & zkurt & Kurtosis of height distribution \\
\hline & zentropy & Normalized Shannon diversity index of height distribution \\
\hline \multirow{17}{*}{ 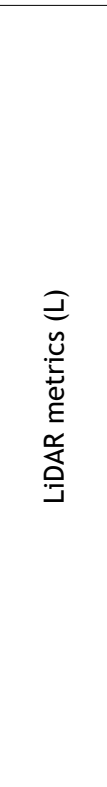 } & zpcum1 & Cumulative percentage of return in the $1^{\text {st }}$ layer \\
\hline & zpcum2 & Cumulative percentage of return in the $2^{\text {nd }}$ layer \\
\hline & zpcum3 & Cumulative percentage of return in the $3^{\text {rd }}$ layer \\
\hline & zpcum4 & Cumulative percentage of return in the $4^{\text {th }}$ layer \\
\hline & zpcum5 & Cumulative percentage of return in the $5^{\text {th }}$ layer \\
\hline & zpcum6 & Cumulative percentage of return in the $6^{\text {th }}$ layer \\
\hline & zpcum7 & Cumulative percentage of return in the $7^{\text {th }}$ layer \\
\hline & zpcum8 & Cumulative percentage of return in the $8^{\text {th }}$ layer \\
\hline & zpcum9 & Cumulative percentage of return in the $9^{\text {th }}$ layer \\
\hline & isd & Standard deviation of intensity \\
\hline & iskew & Skewness of intensity distribution \\
\hline & ikurt & Kurtosis of intensity distribution \\
\hline & ipcumzq10 & Percentage of intensity returned below the $10^{\text {th }}$ percentile of height \\
\hline & ipcumzq30 & Percentage of intensity returned below the $30^{\text {th }}$ percentile of height \\
\hline & ipcumzq50 & Percentage of intensity returned below the $50^{\text {th }}$ percentile of height \\
\hline & ipcumzq70 & Percentage of intensity returned below the $70^{\text {th }}$ percentile of height \\
\hline & ipcumzq90 & Percentage of intensity returned below the $90^{\text {th }}$ percentile of height \\
\hline \multirow{8}{*}{ 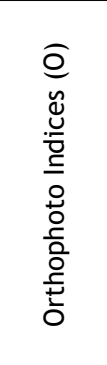 } & m.r.gb & Median $(\mathrm{R} /(\mathrm{G}+\mathrm{B}))$ \\
\hline & m.g.rb & Median $(B /(R+G))$ \\
\hline & m.b.rg & Median $(B /(R+G))$ \\
\hline & m.ndvi & Median (NDVI) \\
\hline & sd.r.gb & Standard deviation of $(R /(G+B))$ \\
\hline & sd.g.rb & Standard deviation of $(B /(R+G))$ \\
\hline & sd.b.rg & Standard deviation of $(B /(R+G))$ \\
\hline & sd.ndvi & Standard deviation of (NDVI) \\
\hline
\end{tabular}

the tree structure and species. In our study, we tested all values from 0.1 to 0.9 .

The second step was to select maximum tree height. We first set a minimum treetop height parameter with a value of $3 \mathrm{~m}$ in order to avoid confusion with local maxima related to herbs and shrubs. For example, in summer 2017, nettles (Urtica sp.) reached as much as $2.5 \mathrm{~m}$ in height. We then used horizontal neighborhood parameters to take into account the minimum distance between one maximum treetop height and nearby crowns of the same height. Considering the important overlap between crowns in the forest, no selection based on minimum distance was applied (i.e., a minimum distance of zero was applied).

The third step was tree crown delineation. To segment the crown extension, we applied a marked-based watershed algorithm. Segments in watershed analysis are delineated by selecting local maxima as the start points of watersheds created by flooding a model surface; this process reverses the CHM. Each local maximum has its corresponding crown (segment). In order to exclude neighboring shrubs from the crown segment, two operations were performed: (i) pixels lower than $3 \mathrm{~m}$ were excluded from the crowns; (ii) inside each crown, we further excluded the pixels lower than the crown proportion multiplied by treetop height. The resulting parameter reflects the ratio between crown depth and tree height, and must be adapted depending on stand structure. We tested all values between 0.1 (the tree crown extended almost to the ground) and 0.9 (the crown was located within the highest $10 \%$ of the tree).

The different parameters tested and their values are listed in Tab. 1.

\section{Classification model: reference data}

In order to build a model capable of separating Acer negundo (AC) and Populus nigra (PN), a reference dataset was created by using the $0.02 \mathrm{~cm}$ resolution orthophotos. Very high resolution imagery, such as provided by UAV, are ideal for photointerpretation (Huylenbroeck et al. 2020). The operator selected a total of 316 disks of $1 \mathrm{~m}$ diameter and classified them as AC (157) or PN (159). Although the operator is both a botanist and an experienced GIS operator with exhaustive field knowledge of the study site, classification errors might be present in this reference dataset.

\section{Classification model: variables tested}

In order to classify the two tree species, variables were computed for each delineated crown based on the $\mathrm{CHM}$, the point cloud and the orthophoto intersecting the crown segments. Tab. 2 presents the variables tested sorted by category: tree metrics $(T)$, LiDAR metrics $(L)$ and orthophoto indices (O). We tested different combinations: (i) $\mathrm{T}+\mathrm{L}+\mathrm{O}$; (ii) $\mathrm{T}+\mathrm{L}$; (iii) $\mathrm{L}+\mathrm{O}$; (iv) $\mathrm{T}$ + O; (v) T; (vi) L; (vii) O. This made seven possible combinations mixed with nine 
Fig. 5 - Overall accuracy (\% on the $y$-axis) of the metrics groups tested (on the $x$-axis) according to crown proportion (values in gray horizontal) and Gaussian filter (values in gray vertical). Metrics groups tested were: Tree metrics $(T)$, LiDAR metrics $(\mathrm{L})$ and Orthophotos indices $(\mathrm{O})$. Combinations tested were: $\mathrm{T}+\mathrm{L}+\mathrm{O}, \mathrm{T}+\mathrm{L}, \mathrm{L}+\mathrm{O}, \mathrm{T}+\mathrm{O}, \mathrm{T}, \mathrm{L}$, $O$. White rectangles correspond to the number of trees used for training and validation. Green dots correspond to an accuracy > $94 \%$.

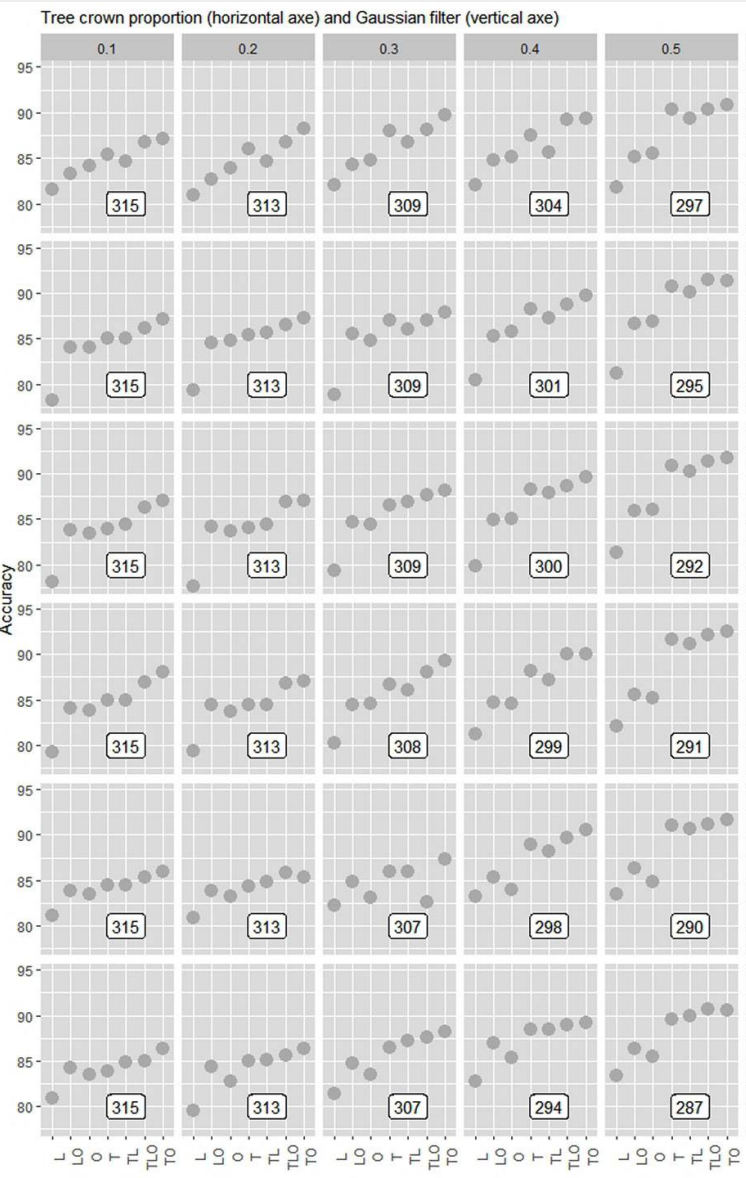

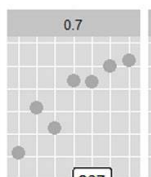
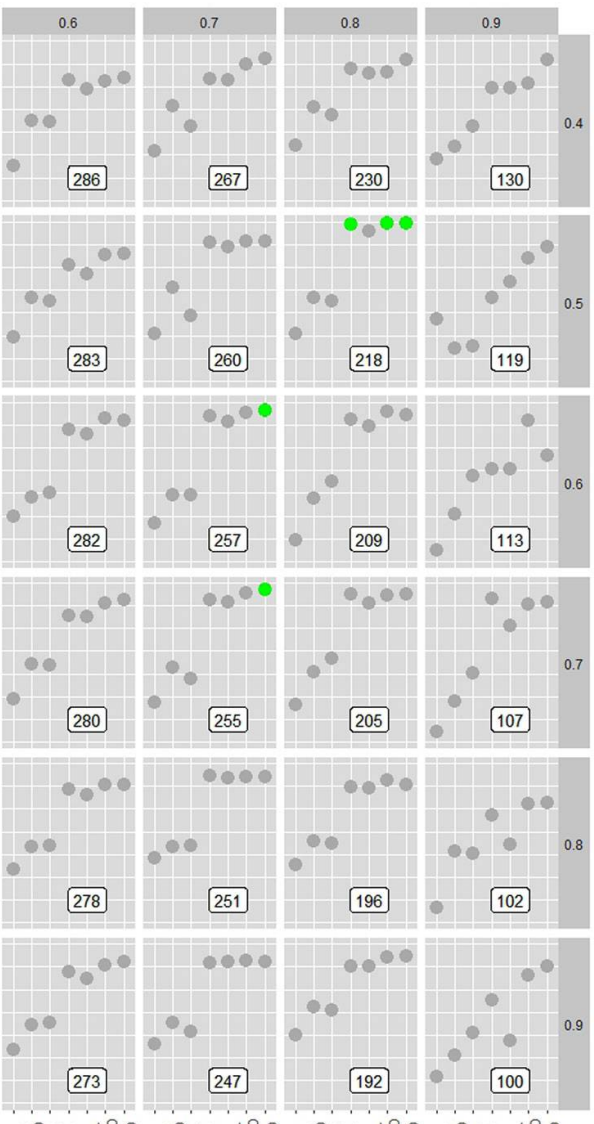

possibilities for the Gaussian filter and nine possibilities for the crown proportion (567 processes).

Direct height variables such as CHM, DTM and point cloud minimum, mean or maximum values were a priori discarded from the analysis, based on our knowledge of fluvial dynamics. Indeed, local island topography changes annually due to sand accretion and erosion. Therefore, keeping a fixed height topography value set on the Mareau-aux-Prés complex would have falsified our extrapolation for the Middle-Loire stretch of the river. Secondly, due to the propagation strategy of the American maple, whose seeds arrive by cohort on exposed river banks (Straigyte et al. 2015), a classification based on height values might have merely reflected the age difference between PN and AC, particularly at our study location in the National Reserve. This would also have led to erroneous extrapolated results for other areas along the Loire River.

\section{Classification model: decision tree}

In order to select discriminating variables, we used Decision Tree in the $R$ party package (Hothorn et al. 2006). To confirm our results, we ran each decision tree 250 times.

\section{Results}

The entire classification process was run on the riparian forests of the Mareau-aux-
Prés islands (Islands: A, B and D - Fig. 4), excluding the hardwood forests. We tested 567 processes and report their overall accuracy and standard deviation in Tab. S1 (Supplementary material).

The accuracy of our classification varied with Gaussian filter and with crown proportion according to metrics group. In Fig. 5, we only present the results from Gaussian filter 0.4 because below this threshold, none of the models succeeded (see Tab. S1 in Supplementary material). Best overall accuracy is represented by green dots for a value greater than $94 \%$. These results concerned all of the metrics groups since the best combinations were: T, TLO, and TO with crown proportions from 0.7 to 0.8 and Gaussian filters from 0.5 to 0.7 . To select the best metrics groups, we had to take into account the number of trees used for training/validation. Indeed, as shown in Fig. 5, we observed that the more the crown proportion and the Gaussian filter increased, the more the number of trees decreased. We then found the best compromise between the best precision and the largest number of trees for training/validation (out of a total of 316 trees selected by visual interpretation). Tab. 3 shows the results of the green dot values and their standard deviations in Fig. 5. We observed that overall accuracy and standard deviations were close and that the number of trees used for training/validation was actually relevant. Finally, we opted for Gaussian filter values of 0.7 and 0.6 , and for a crown proportion value of 0.7 .

Fig. 6 shows that, for both values of Gaussian filter ( $A$ and $B$ ), point cloud height standard deviation was the most robust discriminating variable to distinguish $A C$ from PN. Indeed, even below a height value of just one meter, we consistently detected AC. Above this threshold, a vege-

Tab. 3 - Overall accuracy assessment (mean \pm standard deviation of 250 repetitions) and number of trees in the reference dataset for the metrics groups selected according to the tree segmentation parameters. $(\mathrm{T} / \mathrm{V})$ : training / validation; $(\mathrm{T})$ : tree metrics; (L): LiDAR metrics; (O): Ortophotos indices.

\begin{tabular}{cccccc}
\hline $\begin{array}{c}\text { Gaussian } \\
\text { filter }\end{array}$ & crownProp & $\begin{array}{c}\text { T/N tree } \\
\text { number }\end{array}$ & TLO & TO & T \\
\hline 0.7 & 0.7 & 255 & - & $94.3 \pm 2.7$ & - \\
\hline 0.6 & 0.7 & 257 & - & $94.1 \pm 2.5$ & - \\
\hline 0.5 & 0.8 & 219 & $94.8 \pm 2.5$ & $94.8 \pm 2.4$ & $94.7 \pm 2.3$ \\
\hline
\end{tabular}




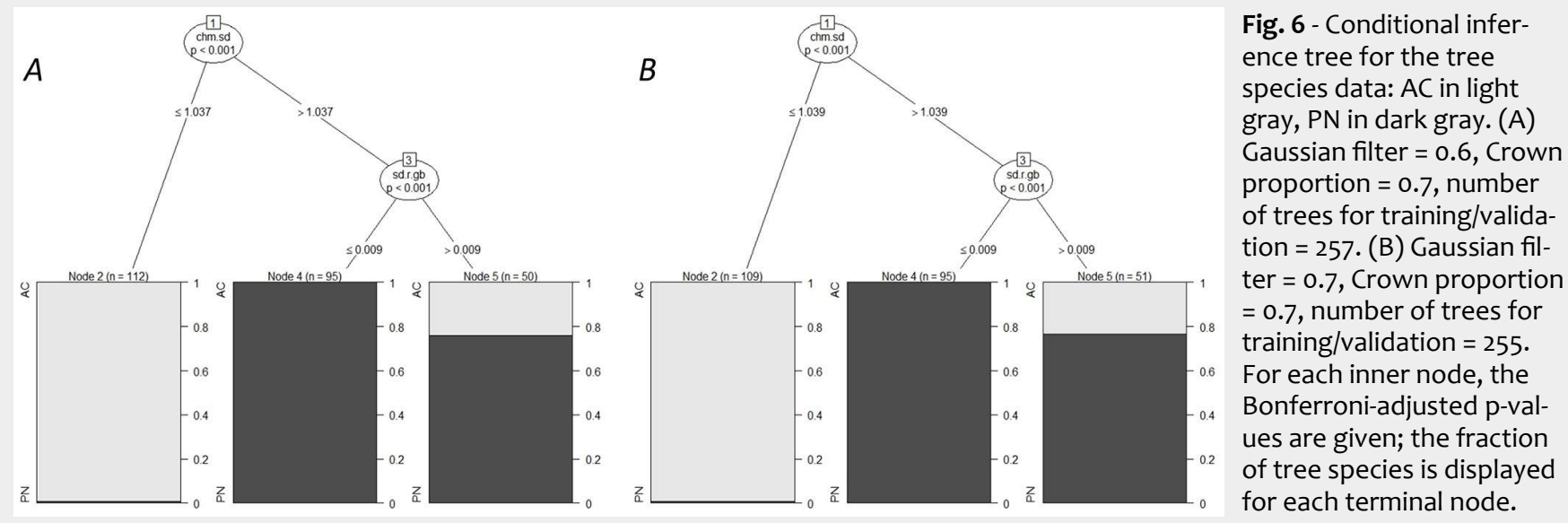

tation index Red / (Green + Blue) standard luvial forest contexts, our results reinforce deviation below 0.009 discriminated PN. the use of LiDAR coupled with photogramHowever, above 0.009 there was an uncertainty of more than $20 \%$ for the prediction of PN.

Fig. 7 presents a prediction map showing that American maple is mainly confined to the outer edges of the islands.

\section{Discussion}

Our results show that, within the National Nature Reserve of Mareau-aux-Prés, point cloud height standard deviation and the standard vegetation index Red / (Green + Blue) predict the presence of American maple (Acer negundo L.) in more than 90\% of the riparian Black poplar (Populus nigra L.) forests.

The retained variables correspond respectively to the groups of tree metrics (point cloud height standard deviation) and the orthophoto indices (standard vegetation index).

In the context of introduced species in al- metry (Manfreda et al. 2018, Huylenbroeck et al. 2020), although comparison with previous research also displays differences. In a Mediterranean riparian forest, Dunford et al. (2009) distinguished five classes including four tree species with an overall accuracy of $91 \%$ from a single RGB image of 13 $\mathrm{cm}$ resolution obtained from UAV. Their reference data consisted of homogeneous terrain units identified on the field with an inclusive sampling and then digitized on the imagery. The overall accuracy dropped to $71 \%$ at the mosaic scale, partly because of radiometry differences in images. The greater accuracy achieved in our case might be explained by the height information added by LiDAR data, as well as the lower number of classes. The radiometry issue might be a problem when analysing larger areas which would require more images and acquisition time with a UAV. With bi-spectral LiDAR data, Laslier et al. (2019) classified eight species of a riparian forest in Normandy (France) with an overall accuracy of $67 \%$. Their study also highlights the importance of elevation metrics for classification. Intensity-related metrics did not bring much improvement in their classification, suggesting that spectral information of LiDAR might not be as straigthforward to use as with imagery. Differences with our results might be explained in part by the fact that they explored a larger gradient of tree species, while we limited ourselves to two species. A wider variety of species can present complex internal canopy structures revealed by LiDAR metrics. When comparing the importance of variables from multispectral and hyperspectral imagery and full-wave form LiDAR for the classification of four tree species in a temperate forest, Heinzel \& Koch (2012) found out that the NIR channel had great importance. Height metrics derived from LiDAR were not selected, but there was one $\mathrm{Li}$ DAR metric linked with the internal struc-

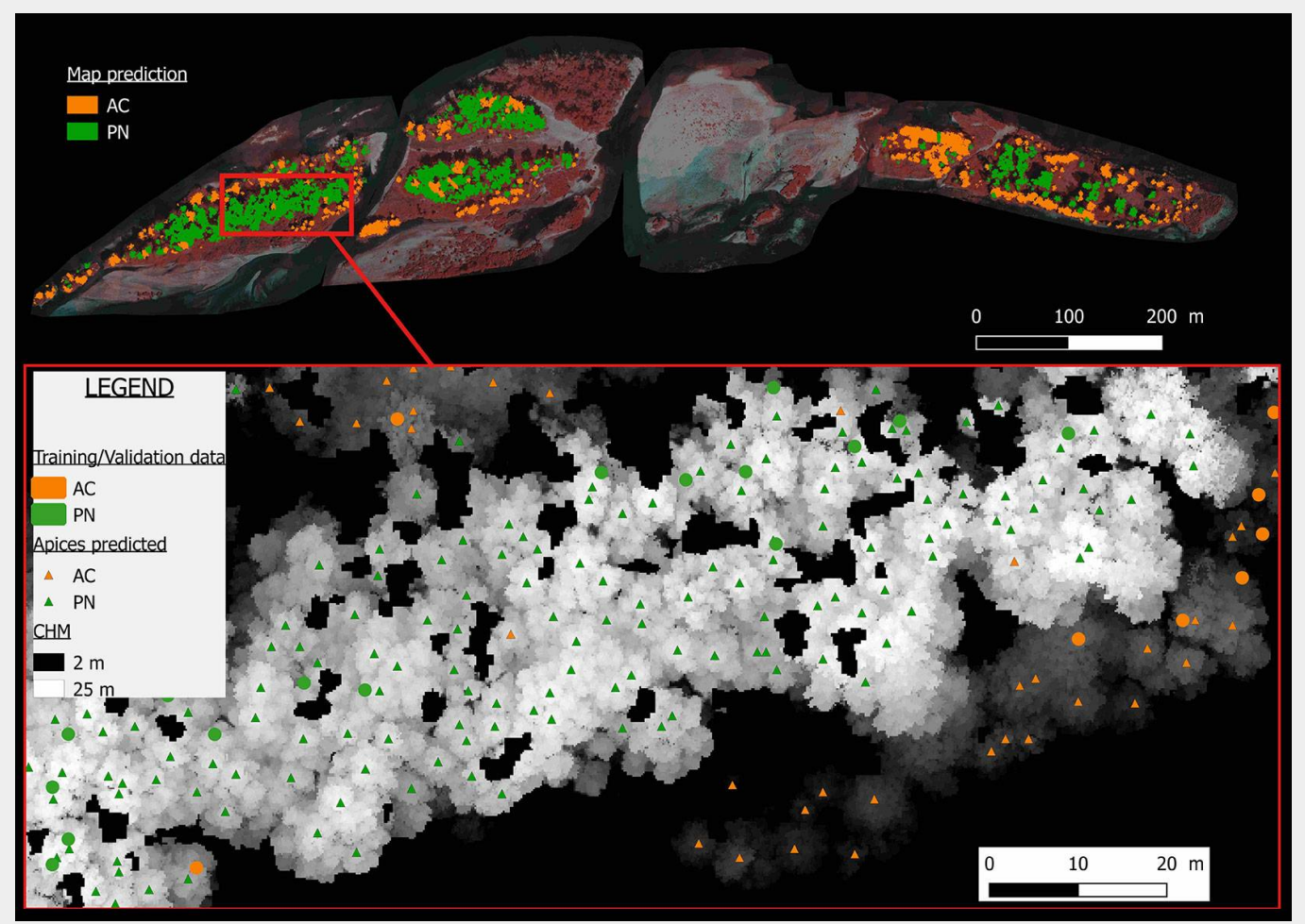

Fig. 7 - Prediction map. Upper part of the figure: prediction map of the American maple (AC, in orange) and Black poplar (PN, in green). Lower part of the figure: an example on a part of the furthest island from the study: circles represent the data interpreted visually, triangles represent the predicted apices, symbology of colors is identical to that previously described. 
ture. Differences with our findings might be due to the fact that they considered both deciduous and coniferous species, which have different reflectance in NIR. Dalponte et al. (2012) showed that LiDAR height metrics improved the classification of mountainous forests into seven tree species compared to multispectral data only. The variability in findings available in the literature shows that depending on species and forest structures, and probably on acquisition period, there are variations in the importance of metrics of different types for species classification.

The results obtained here are rather encouraging regarding the potential for mapping AN dynamics on larger areas with simple variables. Meanwhile, we must be aware of limitations as pointed out by Huylenbroeck et al. (2020) regarding upscaling of results. In the case of longer stretch of river, the relevance of spectral indices might decrease because of issues with radiometric calibration of images and greater variability of forest species, structure and phenology. The use of reference data based only on photointerpretation might also introduce bias or error in the training and validation processes, but it makes also possible to build larger datasets by taking advantage of very high resolution imagery available from UAV. It is clear that this step is highly dependent both on the operator's experience in visual interpretation and his knowledge of the study area, but it is essential to calibrate the predictions as well as possible (Manfreda et al. 2018, Demarchi et al. 2020). The trade-off between variability representation thanks to sample size and noise due to visual interpretation still has to be investigated in order to design cost-efficient operational protocols for the acquisition of reference data for species mapping in larger areas.

However, there are limitations to our findings, especially for Black poplar. Indeed, our results do not take into account an indirect beaver-consumption effect. By consuming Black poplar, the beaver generates holes in the canopy that allow the LiDAR to better penetrate the crowns at the tree scale. If we were to extend our work to all of the Middle-Loire from Nevers to Angers (a distance of about $400 \mathrm{~km}$ ), the results would be at least partially dependent on beaver population density per linear kilometer. How accurate would our classification model be without the presence of the beaver?

One way to solve this problem would be to repeat overflights and test the crown delineation function with tree shape settings. This method was tested on Belgium riparian forests by Michez et al. (2016). Although the image analyses differ according to our study accuracy is greatly increased by repeated overflights. More overflights would likely improve detectability for American maple under the canopy of the taller Black poplars.

Lastly, as Pirotti et al. (2017) show in their study, we could also test other tree crown delineation algorithms such as "Li 2012" and "Dalponte 2016". The Dalponte 2016 algorithm (Dalponte \& Coomes 2016) is similar to the one we used in this study since it starts from rather similar parameters and then segments the CHM. On the other hand, Li's 2012 algorithm ( $\mathrm{Li}$ et al. 2012) does not use a CHM and works directly on the point cloud instead. Though algorithms based directly on the point cloud seem to take more processing time, they could enable researchers to explore the canopy structure of these Loire-island forests.

\section{Conclusion}

American maple (Acer negundo L.) is an introduced species, which competes with the endemic Black poplar (Populus nigra L.). We used an airborne LiDAR scanner and imagery-derived vegetation index data to discriminate American maple from Black poplar with $90 \%$ accuracy on a complex of four islands inside the National Nature Reserve of Saint-Mesmin in the Loire River (France), based on a training and validation dataset obtained by photointerpretation. Mapping the American maple is all the more important since beavers (reintroduced in the 1970s) do not consume it, though it consumes Black poplar. We found that tree crown delineation is optimized by the "treeSegmentation" function from the "lidaRtRee" package (Monnet 2018) running under free $R$ software ( $R$ Development Core Team 2017). We tested two important parameters of this function: the Gaussian filter and crown proportion. The first parameter prevents big branches in a crown being considered as trees. The second optimizes the proportion of the crown relative to the total height. We found that the best values for the Gaussian filter and crown proportion were respectively 0.7 (and 0.6) and 0.7. We also found that the best predictors were point cloud height standard deviation and the standard deviation of a simple vegetation index based on RGB wavelengths, Red/ (Green + Blue).

\section{Acknowledgements}

This study is part of the BioMareau project, funded within the framework of the Loire River Interregional Program 20142020". Funding institutions are the CentreVal de Loire Region (no. 2016-00108348), INRA, IRSTEA and the European Union (Europe being engaged in the Loire basin through the EU operational program of the European Regional Development Fund, no. 2016-EX000604). The BioMareau project has been approved by the CNRS Loire LTER "Zone Atelier Loire" and the regional MIDI (Habitat and Diversity) research network. Michel Chantereau and Damien Hémeray from the National Natural Reserve of SaintMesmin are acknowledged for their interest and their support for science at the Mareau-aux-prés Islands.
We also thank Vicki Moore for her relevant editorial remarks.

\section{References}

Asner GP, Knapp DE, Kennedy-Bowdoin T, Jones MO, Martin RE, Boardman J, Hughes RF (2008). Remote sensing of native and invasive species in Hawaiian forests. Remote Sensing of Environment 112: 1942-1945. - doi: 10.1016/j.rse.2007. 11.016

Balenović I, Alberti G, Marjanović H (2013). Airborne laser scanning - the status and perspectives for the application in the South-East European forestry. South-East European Forestry 4 (2): 59-79. - doi: 10.15177/seefor.13-07

Berg C, Drescher A, Essl F (2017). Using relevébased metrics to explain invasion patterns of alien trees in temperate forests. Tuexenia 37: 127-142. [online] URL: http://d-nb.info/115114015 $5 / 34$

Beslin O, Gazeau J-C (2016). Système d'Information des Évolutions du Lit de la Loire et de ses affluents. Typologie des habitats du SIEL 2 . Guide de terrain et de lecture pour la cartographie [Information System of the Evolutions of the Loire riverbed and its tributaries. SIEL Habitat Typology 2. Field and Reading Guide for Mapping]. Conservatoire National du Bassin Parisien, délégation Centre-Val de Loire, Orléans, France, pp. 1-27. [in French]

Campbell L, Coops N, Saunders S (2017). LiDAR as an advanced remote sensing technology to augment ecosystem classification and mapping. Journal of Ecosystems and Management 17 (1): 1-13. [online] URL: http://jem-online.org/ forrex/index.php/jem/article/view/588

Dalponte M, Bruzzone L, Gianelle D (2012). Tree species classification in the Southern Alps based on the fusion of very high geometrical resolution multispectral/hyperspectral images and LiDAR data. Remote Sensing of Environment 123: 258-270. - doi: 10.1016/j.rse.2012.03.0 13

Dalponte M, Coomes DA (2016). Tree-centric mapping of forest carbon density from airborne laser scanning and hyperspectral data. Methods in Ecology and Evolution 7: 1236-1245. - doi: 10.1111/2041-210X.12575

Demarchi L, Kania A, Ciezkowski W, Piórkowski H, Oswiecimska-Piasko Z, Chormanski J (2020). Recursive feature elimination and random forest classification of Natura 2000 grasslands in lowland river valleys of Poland based on airborne hyperspectral and LiDAR data fusion. Remote Sensing 12: 1-33. - doi: 10.3390/rs12111842 Dufour S, Bernez I, Betbeder J, Corgne S, Hubert-Moy L, Nabucet J, Rapinel S, Sawtschuk J, Trollé C (2013). Monitoring restored riparian vegetation: how can recent developments in remote sensing sciences help? Knowledge and Management of Aquatic Ecosystems 410 (10): 115. - doi: 10.1051/kmae/2013068

Dumas Y (2019). Que savons-nous de l'Erable négondo (Acer negundo L., 1753)? [What do we know about American maple (Acer negundo L., 1753)?]. Naturae (10): 257-283.

Dunford R, Michel K, Gagnage M, Piégay $H$, Trémelo M-L (2009). Potential and constraints of unmanned aerial vehicle technology for the characterization of Mediterranean riparian forest. International Journal of Remote Sensing 30 
(19): 4915-4935. - doi: 10.1080/014311609030230 25

Grivel S, Gautier E (2012). Mise en place des îles fluviales en Loire moyenne, du $19^{\mathrm{e}}$ siècle à aujourd'hui [Establishment of fluvial islands in the middle Loire, from the $19^{\text {th }}$ century to today]. Cybergeo, European Journal of Geography, Document no. 615. [in French] - doi: 10.4000/cyber geo.25451

Gurnell A (2014). Plants as river system engineers. Earth Surface Processes and Landforms 39 (1): 4-25. - doi: 10.1002/esp.v39.1

Heinzel J, Koch B (2012). Investigating multiple data sources for tree species classification in temperate forest and use for single tree delineation. International Journal of Applied Earth Observation and Geoinformation 18: 101-110. doi: 10.1016/j.jag.2012.01.025

Hervé J-C, Wurpillot S, Vidal C, Roman-Amat B (2014). L'inventaire des ressources forestières en France: un nouveau regard sur de nouvelles forêts [Inventory of forest resources in France: a new look at new forests]. Revue Forestière Française 66 (3): 247-260. [in French] - doi: 10.4267/2042/56055

Hothorn T, Hornik K, Zeileis A (2006). Unbiased recursive partitioning: a conditional inference framework. Journal of Computational and Graphical Statistics 15 (3): 651-674. - doi: 10.119 8/106186006X133933

Huylenbroeck L, Laslier M, Dufour S, Georges B, Lejeune P, Adrien M (2020). Using remote sensing to characterize riparian vegetation: a review of available tools and perspectives for managers. Journal of Environmental Management 267: 1-19. - doi: 10.1016/j.jenvman.2020.11 0652

Jaafar WSWM, Woodhouse IH, Silva CA, Omar H, Abdul Maulud KN, Hudak AT, Klauberg C, Cardil A, Mohan M (2018). Improving individual tree crown delineation and attributes estimation of tropical forests using airborne LiDAR data. Forests 9 (12): 1-23. - doi: 10.3390/f9120759

Laslier M, Hubert-Moy L, Dufour S (2019). Mapping riparian vegetation functions using $3 \mathrm{D}$ bispectral LiDAR data. Water 11 (3): 483. - doi: 10.3390/w11030483

Lindberg E, Holmgren J (2017). Individual tree crown methods for $3 D$ data from remote sensing. Current Forestry Report 3: 19-31. - doi: 10.1007/s40725-017-0051-6

Li W, Guo Q, Jakubowski MK, Kelly M (2012). A Naiman RB, Décamps H, McClain ME (2005). Ri- new method for segmenting individual trees from the lidar point cloud. Photogrammetric Engineering and Remote Sensing 78: 75-84. doi: 10.14358/PERS.78.1.75

Manfreda S, McCabe MF, Miller PE, Lucas R, Pajuelo Madrigal V, Mallinis $G$, Ben Dor E, Helman D, Estes L, Ciraolo G, Müllerová J, Tauro F, De Lima MI, De Lima JLMP, Maltese A, Frances F, Caylor K, Kohv M, Perks M, Ruiz-Pérez G, Su Z, Vico G, Toth B (2018). On the use of unmanned aerial systems for environmental monitoring. Remote Sensing 10: 1-33. - doi: 10.3390/rs1004 0641

Mei C, Durrieu S (2004). Tree crown delineation from digital elevation models and high resolution imagery. In: Proceedings of the ISPRS Working Group part 8/2. Freiburg (Germany) 36 Oct 2004. The International Archives of the Photogrammetry, Remote Sensing, vol. 36, pp. 6. [online] URL: http://www.researchgate.net/ publication/228986087

Michez A, Piégay H, Lisien J, Claessens H, Lejeune $P$ (2016). Classification on riparian forest species and health condition using muti-temporal and hyperspatial imagery from unmanned aerial system. Environmental Monitoring and Assessment 188 (146): 1-19.

Monnet J-M, Mermin E, Chanussot J, Berger F (2010). Tree top detection using local maxima filtering: a parameter sensitivity analysis. In: Proceedings of "Silvilaser 2010 - $10^{\text {th }}$ International Conference on LIDAR Applications for Assessing Forest Ecosystems". Freiburg (Germany) 14 Sep 2010, pp. 9. [online] URL: http:// hal.archives-ouvertes.fr/hal-00523245/

Monnet J-M (2011). Caractérisation des forêts de montagne par scanner laser aéroporté: estimation de paramètres de peuplement par régression SVM et apprentissage non supervisé pour la détection de sommets [Using airborne laser scanning for mountain forests mapping: Support vector regression for stands parameters estimation and unsupervised training for treetop detection]. PhD thesis, Grenoble Images Parole Signal Automatique Department, Université de Grenoble Alpes, France, pp. 187. [online] URL: http://www.theses.fr/2011GRENT056 Monnet J-M (2018). lidaRtRee, forest analysis with airborne laser scanning (Lidar) data. Web site. [online] URL: http://gitlab.irstea.fr/jeanmatthieu.monnet/lidaRtRee paria: ecology, conservation, and management of streamside communities. Elsevier Academic Press, London, UK, pp. 418.

Pirotti F, Kobal M, Roussel J-R (2017). A comparison of tree segmentation methods using very high density airborne laser scanner data. Inter national Archives of the Photogrammetry, Remote Sensing and Spatial Information Sciences XLII-2/W7: 285-290. - doi: 10.5194/isprs-archivesXLII-2-W7-285-2017

R Development Core Team (2017). R: a language and environment for statistical computing. $R$ Foundation for Statistical Computing, Vienna. [online] URL: http://www.r-project.org/

Rodrigues S, Bréhéret J-G, Macaire J-J, Greulich S, Villar M (2006). In-channel woody vegetation controls on sedimentary processes and the sedimentary record within alluvial environments: a modern example of an anabranch of the River Loire, France. Sedimentology 54 (1): 223-242. - doi: 10.1111/j.1365-3091.2006.00832.x

Rouse J, Haas RH, Schell JA, Deering DW (1973). Monitoring vegetation systems in the great plains with ERTS. In: Proceeding of the " $3^{\text {rd }}$ ERTS Symposium". Washington (DC, USA) 10-14 Dec 1973. NASA SP-351 1, US Government Printing Office, Washington, DC, USA, pp. 309-317.

Straigyte L, Cekstere G, Laivins M, Marozas V (2015). The spread, intensity and invasiveness of the Acer negundo in Riga and Kaunas. Dendrobiology 74: 157-168. - doi: 10.12657/denbio.0 74.016

Wehr A, Lohr U (1999). Airborne laser scanning an introduction and overview. ISPRS Journal of Photogrammetry and Remote Sensing 54: 6882. - doi: 10.1016/So924-2716(99)00011-8

Zhen Z, Quackenbush L, Zhang L (2016). Trends in automatic individual tree crown detection and delineation evolution of LiDAR data. Remote Sensing 8 (4): 333. - doi: 10.3390/rs80403 33

\section{Supplementary Material}

Tab. S1 - Overall accuracy (\%) and standard deviation of the metrics groups tested according to crown proportion and Gaussian filter.

Link: Martin_3237@supplo01.pdf 